\section{Bilateral chronic subdural haematoma: a reversible cause of parkinsonism}

\author{
S Suman S Meenakshisundaram \\ P Woodhouse
}

J R Soc Med 2006;99:91-92

Elderly patients with chronic subdural haematoma most commonly present with altered mental status and focal neurological deficit. ${ }^{1}$ New onset parkinsonism and worsening of pre-existing Parkinson's disease are both uncommon but recognized presenting features of chronic subdural haematoma. ${ }^{2-5}$

\section{CASE HISTORY}

An 81-year-old man suffered blunt trauma to his chest resulting from a road traffic accident. On admission a chest $\mathrm{X}$-ray showed multiple rib fractures but a computerized tomography scan of the head ruled out any post-traumatic lesion. He had a background diagnosis of mild Alzheimer's dementia for which he was being treated with galantamine. He lived a reasonably independent life with his wife and was driving the car himself when the accident occurred. After a fortnight he was discharged from hospital.

Two months later he developed progressive deterioration in mobility. His wife noted an increasing level of forgetfulness and intermittent episodes of confusion. His general practitioner noted a shuffling gait and rigidity affecting lower limbs and made a working diagnosis of parkinsonism. A trial of Madopar (Levodopa and benserazide: $62.5 \mathrm{mg}$ three times a day for 2 weeks) was given by the GP but this failed to improve the situation and he became virtually bed-bound. He was referred back to the hospital for further investigation.

On admission he was confused and marked rigidity affecting upper and lower limbs was detected. No resting tremor was noted but gait could not be tested, as he was unable to get out of bed. In view of the clinical presentation a computerized tomography scan of the head was repeated which showed bilateral fronto-parietal chronic subdural

Department of Medicine for the Elderly, Norfolk \& Norwich University Hospital, Norwich NR4 7UY, UK

Correspondence to: Dr S Suman

E-mail: sanjaysuman@doctors.org.uk haematoma (Figure1 $a, b$ ). He was referred to the regional neurosurgical centre where he underwent bilateral burrhole drainage. Postoperative recovery was unremarkable and on examination there was complete resolution of previous rigidity affecting upper and lower limbs. He was able to converse normally with his wife and began walking with the aid of a stick by third postoperative day. A week later he was discharged from the hospital having regained his previous level of mobility and independence with activities of daily living.

\section{COMMENT}

Chronic subdural haematoma commonly occurs in the older population without any history of direct head trauma or following minor trauma. As with our case, a head computerized tomography done immediately after trauma may be normal. Parkinsonism suggested by extrapyramidal rigidity, bradykinesia and resting tremor are uncommon but

(a)

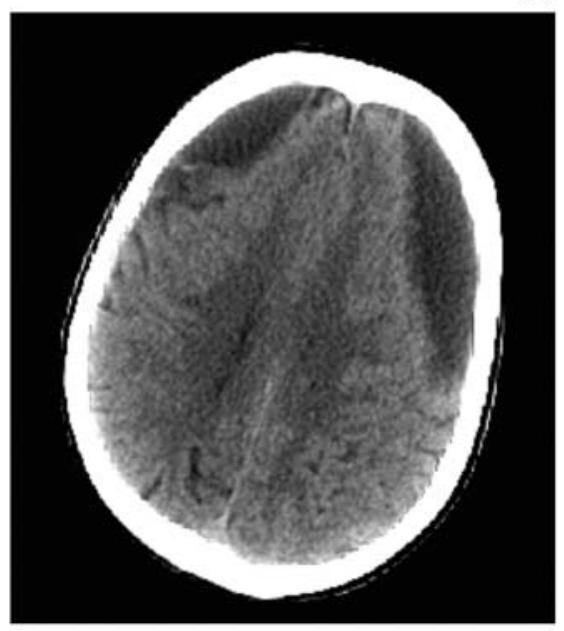

(b)

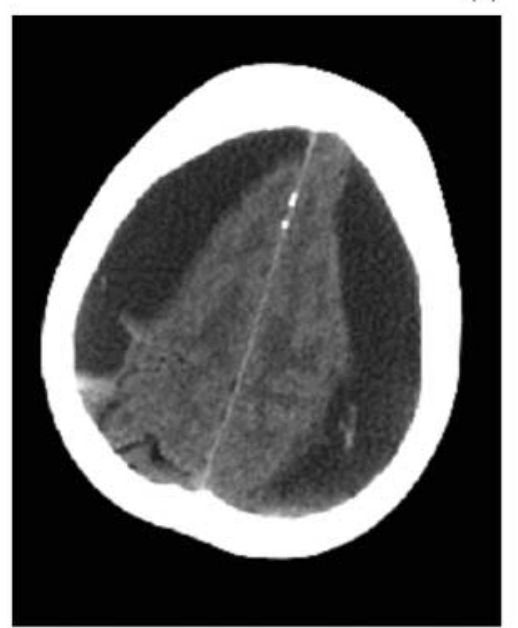

Figure 1 CT head shows bilateral chronic subdural haematoma 
recognized presenting features of chronic subdural haematoma..$^{2-5}$ These features develop over a period of few weeks to months and extrapyramidal rigidity is often symmetrical in limbs. This is in contrast to idiopathic Parkinson's disease, which typically progresses slowly over a number of years. Moreover, rigidity affecting one side more than the other is usual in Parkinson's disease. chronic subdural haematoma has also been known to cause sudden clinical deterioration in patients with previously wellcontrolled Parkinson's disease. ${ }^{5}$ The underlying mechanisms for new appearance or worsening of pre-existing extrapyramidal features in patients with chronic subdural haematoma include a direct pressure effect of haematoma on basal ganglion structures or by altered neurotransmitter function. ${ }^{6}$ Surgical evacuation of haematoma results in prompt resolution of parkinsonism suggesting a cause and effect relation.
In elderly patients, a high index of suspicion and computerized tomography of the head facilitates the diagnosis of chronic subdural haematoma, which in most cases is amenable to surgical treatment.

\section{REFERENCES}

1 Asghar M, Adhiyaman V, Greenway MW, Bhowmick BK, Bates A. Chronic subdural haematoma in the elderly-a North Wales experience. J R Soc Med 2002;95:290-2

2 Krul JM, Wokke JH. Bilateral subdural hematoma presenting as subacute parkinsonism. Clin Neurol Neurosurg 1987;89:107-9

3 Sandyk R. Parkinsonism caused by chronic subdural haematoma. A case report. S Afr Med J 1982;61:595-6

4 Hageman AT, Horstink MW. Parkinsonism due to a subdural hematoma. Mov Disord 1994;9:107-8

5 Chou SM, Gutmann L. Deteriorating parkinsonism and subdural hematomas. Neurology 2001;57:1295

6 Sandyk R, Kahn I. Parkinsonism due to subdural hematoma. Case report. J Neurosurg 1983;58:298-9 